\title{
GAGURITAN RUSAK BULELENG SEBUAH KAJIAN NILAI-NILAI
}

\author{
Ni Nyoman Kertiasih \\ Universitas Warmadewa \\ nn.kertiasih@gmail.com
}

\begin{abstract}
ABSTRAK
Gaguritan Rusak Buleleng, koleksi Gedong Kirtya dapat memberikan gambaran mengenai peristiwa sejarah eroik di Bali Utara. Peristiwa itu terjadi pada tahun 1846, menyebabkan kerajaan Buleleng jatuh ke tangan penjajah Belanda. Pada masa itu situasi menunjukkan bahwa kekuatan politik Belanda sedang meluaskan pengaruhnya di Kepulauan Indonesia. Bali mulai menjadi sasaran pemerintah kolonial di pertengahan abad ke-19. Adapun nilai-nilai yang dapat digali dari cerita GRB dapat disebutkan: nilai persatuan, kebersamaan, kepahwanan, nilai pendidikan, nilai religious, nilai politik/diplomasi, dan nilai kompetisi kuasa politik antar kekuatan politik. Sebagai bagian dari model pendekatan analisis konten, dapat disebutkan, berbagai konteks situasi, system nilai budaya berpengaruh di dalamnya. Dalam hubungan itu, tampak berpengaruh system nilai guyub, persatuan orang Bali, nilai kompetisi politik raja-raja Bali, nilai tradisi masyarakat Bali, dan system politik colonial yang sedang berkembang.
\end{abstract}

Kata kunci: Buleleng; geguritan rusak; peristiwa sejarah

\begin{abstract}
Gaguritan Rusak Buleleng, Gedong Kirtya collection can provide an overview of heroic historical events in North Bali. The incident occurred in 1846, causing the kingdom of Buleleng fell into the hands of the Dutch invaders. At that time the situation showed that Dutch political power was expanding its influence in the Indonesian Archipelago. Bali began to be targeted by the colonial government in the mid-19th century. The values that can be extracted from the GRB story can be mentioned: the value of unity, togetherness, leadership, educational values, religious values, political / diplomacy values, and the value of competition for political power between political forces. As part of the content analysis approach model, it can be mentioned, various contexts of the situation, cultural value systems influence in it. In that connection, it seems to influence the system of values of harmony, unity of the Balinese, the value of the political competition of the kings of Bali, the value of traditional Balinese traditions, and the colonial political system that is developing.
\end{abstract}

Keywords: Buleleng; broken geguritan; historical event

\section{PENDAHULUAN}

Website merupakan salah satu media promosi yang berkaitan erat dengan internet. Gaguritan Rusak Buleleng (disingkat GRB) adalah sebuah karya sastra (Bali) dalam bentuk puisi (gaguritan), yang mengungkapkan suatu peristiwa heroic, kepahlawanan yang terjadi di Kerajaan Buleleng (Bali Utara) pada pertengahan abad ke-19 (tahun 1846). Sebagai karya sastra dalam bentuk lontar (berbahasa Bali) naskah itu diperoleh (disimpan) di Perpustakaan Lontar Gedong Kirtya, Singaraja, dengan nomor kropak Vc 1035, dengan nama Rusak Buleleng. Lontar itu (berbahasa Bali) kemudian diambil dan diterjemahkan ke dalam Bahasa Indonesia oleh I Putu Geria. Oleh I Putu Geria, naskah itu kemudian diberi nama, Gaguritan Rusak Buleleng. Nama "Gaguritan" ditambahkannya, tampak karena naskah itu ditulis dalam bentuk puisi/tembang-pupuh (gaguritan). Disebutkan, gaguritan adalah sebuah jenis (genre) dalam kesusastraan Bali yang lumrah terdapat dikalangan masyarakat Bali. Gaguritan itu dapat berbentuk terjemahan 
dari Bahasa yang bukan Bali (seperti Jawa, ke dalam Bahasa Bali, lalu disadur), atau memang berupa karya Bali asli yang berbentuk gaguritan (Van Eck, dikutip dari Agastia, 1980: 4). Menurut Kamus Bali-Indonesia, gaguritan berarti, "saduran cerita yang berbentuk tembang (pupuh) (Panitia Penyusun Kamus, 1978: 223).

Dalam karya pendahuluan ini, penulis tidak berusaha melacak berapa banyak karya gaguritan Rusak Buleleng yang ada di Bali, tetapi lebih terfokus pada yang terdapat/tersimpan di Gedong Kirtya, Singaraja. Di sana terdapat satu naskah tentang Gaguritan Rusak Buleleng, selain ada juga yang disebut sebagai Babad Buleleng. Yang kedua ini, berupa cerita panjang yang menggambarkan mengenai riwayat raja-raja Buleleng, keturunan Panji Sakti, yang disebut berawal dari turunan (putra) Dalem Gelgel (Dalem Sagening) sekitar pertengahan abad ke16. Diceritakan, ada seorang wanita dari Buleleng (Desa Panji) bernama Si Luh Pasek menjadi sahaya di Kerajaan Gelgel. Pada masa itu memerintah sebagai raja, Ida Dalem Sagening. Rupanya raja (Dalem Sagening) jatuh cinta pada wanita Si Luh Pasek itu. Kemudian diketahui bahwa Luh Pasek hamil, dan Dalem Sagening sadar diri, telah menyebabkan Si Luh Pasek mengandung. Oleh karena itu, merasa sudah tua, raja menyerahkan Si Luh Pasek itu (sedang hamil) kepada seorang elit kerajaan bernama Arya Jlantik (Ki Gusti Ngurah Jlantik). Ketika lahir, anak laki-laki, berparas tampan, diberi nama Ki Barak Panji, yang kemudian bergelar Ki Gusti Ngurah Panji, menjadi cakal bakal raja-raja Buleleng yang bersambungan darah dengan Raja Gelgel dan raja lainnya di Bali. Kemudian, Raja Karangasem - karena merasa kuat, menaklukkan Buleleng dan menggantikan rajarajanya dengan raja turunan Karangasem (Lihat, W.Simpen AB, Babad Kerajaan Buleleng).

Kembali kepada Gaguritan Rusak Buleleng, sebagai karya sastra bercerita mengenai keadaan, kekacauan di Kerajaan Buleleng, pada awal kedatangan kekuasaan Belanda di Bali di abad ke-19. Pada masa itu, di Buleleng memerintah raja dan patih turunan Karangasem. Pengaruh kekuasaan Belanda mulai masuk ke Bali, karena raja-raja Bali telah melakukan kesepakatan dengan Pemerintah Jajahan (Belanda). Dengan perjanjian itu, Pemerintah Belanda mengapuskan Hukum Tawan Karang raja-raja Bali, yang menghalangi masuknya kapal-kapal dagang asing masuk tanpa izin. Berani masuk ke daerah Bali tanpa izin, kapal itu akan dirampas isinya. Dengan perjanjian itu, yang dibuat pada tahun 1840-an antara raja-raja Bali dan Lombok dan Pemerintah Belanda di Batavia, maka Belanda merasa telah bebas hambatan untuk masuk ke wiyaha perairan Bali. Akan tetapi Raja Buleleng, dengan ketokohan patihnya I Gusti Ketut jelantik, - kemudian - tidak mengakui apa yang telah disepakati, karena merasa menjadikan wilayahnya menjadi milik Belanda. Hal itu membawa konflik berkepanjangan dengan pemerintah Belanda, seterusnya terjadi perang besar yang menghancurkan Kerajaan Buleleng. Dalam kaitan itu tampak terjadi pergolakan nilai-nilai pada diri tokohtokoh/raja-raja Bali dalam membela sikap mana yang dipandang benar atau salah. Memahami keadaan itu, tampak penting menulis Gaguritan Rusak Buleleng dengan melihat dari sudut nilai-nilai.

Tujuan dari tulisan ini adalah untuk menggali nilai-nilai yang terkandung di dalam Gaguritan Rusak Buleleng (GRB), yang ditulis setelah peristiwa, "Perang Buleleng" (1846) terjadi. GRB memberikan gambaran tentang terjadi konflik, kemudian perang besar antara pasukan kerajaan melawan pasukan Belanda. Di sini, Kerajaan Buleleng sebagai kekuatan yang bertahan, memegang hak-hak sebagai penguasa pribumi, sedangkan pihak Belanda merasa mempunyai hak di Buleleng sebagai hasil dari kesepakatan yang dibuat antara kedua belah pihak. Sementara raja-raja Bali lainnya (Karangasem, Klungkung, Badung, Lombok) mengambil sikap berhati-hati, karena perjanjian sudah terlanjur dilakukan. Dilema memang. Tetapi di Buleleng atas kekerasan pikiran patih raja, I Gusti Ketut Jelantik, raja bertahan, tidak mau menyerah, karena perjanjian yang dibuat sebelumnya itu, pastinya akan membuat kerajaan tunduk di bawah pemerintahan penjajah Belanda.

Maka tujuan dari penulisan ini adalah menggali nilai-nilai, nilai budaya yang terkandung di dalam pergolakan yang terjadi. Disebutkan nilai budaya merupakan tingkat 
yang paling abstrak dari adat. "Suatu system nilai budaya terdiri dari konsepsi-konsepsi yang hidup dalam alam pikiran sebagaian besar dari warga masyarakat, mengenai hal-hal yang harus mereka anggap amat bernilai dalam hidup. Sistem nilai budaya biasanya berfungsi sebagai pedoman tertinggi bagi kelakuan manusia" (Lihat, Kuntjaraningrat, 1974: 32). Dari kajian GRB, akan dicoba menggali nilainilai apa yang terkandung di dalamnya, yang mendukung sikap kedua pihak mesti berperang mempertahankan pendiriannya.

\section{METODE}

Seperti diungkapkan di atas, Gaguritan Rusak Buleleng merupakan karya sastra berbentuk pupuh dan bait-bait pupuh, berbahasa Bali, diterjemahkan ke dalam Bahasa Indonesia. Dari segi metode, dilakukan pembacaan secara cermat atas GRB, mengurai, lalu dibangun suatu synopsis, ringkasan yang jelas dari isi/temanya. Sinopsis diurai menjadi bagian-bagian dari GRB, pertama (pupuh durma) dan kedua (pupuh sinom), sehingga jelas gambaran nilai yang terkandung di dalamnya.

Sebagai penyajian analisis, penulisan dibagi ke dalam bab-bab, seperti: Bab I. Pendahuluan, Bab II Sinopsis, Bab III Analisis GRB, yang menguraikan tentang nilai-nilai yang terkandung di dalamnya. Selanjutnya Bab IV Kesimpulan. Dengan demikian, diharapkan penulisan GRB mengangkat nilai-nilai dari karya sastra itu.

\section{PEMBAHASAN Sinopsis GRB}

Gaguritan Rusak Buleleng (GRB), yang digunakan di sini adalah yang tersimpan di Gedong Kirtya, Singaraja, yang kemudian ditulis kembali dan diterjemahkan oleh I Putu Geria. GRB terdiri atas 27 lembar lontar (ditulisi bolak-balik), dua pupuh (tembang) yakni: pupuh Durma dan pupuh Sinom. Tembang Durma terdiri atas 106 pada (bait) dan tembang Sinom berisi 95 pada (bait). Dilihat dari segi isinya, dapat diringkas sebagai berikut.

Bagian pertama (pupuh Durma), menceritakan tentang usaha pengarang menulis gaguritan itu, menceritakan tentang perang (di Buleleng), berasal dari kabar yang didengar, soal raja Buleleng bertentangan dengan Belanda. Dikabarkan juga bahwa raja-raja lain di Bali dan Lombok bersahabat dengan Belanda. Tetapi disebut bahwa Belanda, melalui Gubernur Jendralnya, sepertinya mencari-cari kesalahan, dengan membuat perjanjian (pasobaya), menghapuskan hukum tawan karang di Bali, sehingga ia (Belanda) bebas berlayar. Demikian dibuat perjanjian tertulis, diberikan kepada semua raja di Bali dan Lombok. Tetapi ada dua kerajaan di Bali (Karangasem dan Buleleng) - sedang bermusuhan - ke Lombok, menjadi ganjalan dalam perjanjian - menolak mengikuti perjanjian.

Maka ketika ada perahu lewat di Pantai Sangsit (perairan Buleleng), tahun 1844, semua isinya dirampas, karena Buleleng menjalankan hukum tawan karang, di bawah pimpinan Patih I Gusti Ketut Jelantik. Pihak Belanda menjadi marah, dan meminta raja mengganti rugi barang-barang yang dirampas. Dan berusaha mendekati Patih Jelantik, juga melalui Raja Klungkung, agar mau berdamai, tetapi harus membayar ganti rugi. Usaha itu gagal. Bahkan Ketut Jelantik menghardik, mencaci maki, menghina utusan Belanda yang dipertemukan di Puri Klungkung. Surat-surat utusan Pemerintah Belanda dirobek-robek dengan keris oleh I Gusti Ketut Jelantik. Ia bersikukuh, bahwa kapal itu telah melanggar aturan pelabuhan (pabean) dengan masuk tanpa izin. Karena itu dijarah. Tjokorda Klungkung, yang berusaha mendamaikannya, tidak dapat menasehatinya. Sementara itu, dikabarkan bahwa Raja (I Gusti Made Karangasem) banyak diam, menyerahkan saja kepada patihnya. Sebaliknya, Ketut Jelantik menantang, kapan saja kalau mau datang menyerang akan dihadapi secara kesatria.

Oleh karena itu, pihak Pemerintah Belanda di Jawa (Besuki) menjadi sangat marah, akan mempertimbangkan langkah yang akan dilakukan. Penguasa Belanda di Besuki (Tuan Mayor) segera mempersiapkan pasukan untuk menyerang Buleleng. Tetapi disebut, Tuan Mayor bijaksana, terlebih dahulu melakukan pendekatan kepada raja-raja lainnya di Bali (Klungkung, Karangasem), namun gagal. Disebut pada suatu hari (Sasih Kasa) akan berangkat ke Bali membawa pasukan besar, lengkap dengan mesiu, obat-obat peluru. 
Kemudian disebutkan, bahwa kapal-kapal sudah datang di Pabeyan, serdadu sudah banyak yang turun (sekitar 600 orang), keadaan menjadi panik. Peristiwa itu terjadi tahun 1846.

Selanjutnya pada bagian kedua (akhir) dari Tembang Durma ini, digambarkan bagaimana keadaan di pantai, sudah ramai dengan pasukan Belanda. Pada saat itu pula raja mengirim utusan ke Pabeyan agar bertemu dengan pimpinan pasukan Belanda. Pasukan, serdadu Belanda kelihatan berbaris menuju sasaran/desa Buleleng), sementara di desa Buleleng telah dipasang juga penjagaan dari rakyat (orang-orang Bali, Bugis) yang setia kepada raja. Di sini bertindak I Gusti Ketut Jelantik sebagai pemimpin pasukan Bali. Sorak sorai gemuruh dari kedua belah pihak. Situasi semakin panas, peluru pasukan Belanda pun menyasar pasukan raja Buleleng. Mereka mengurung dari kanan dan kiri, perkelahian secara dekat pun terjadi menggunakan senjata pedang, tombak. Tetapi pasukan kerajaan menjadi kocar-kacir, tidak kuat dan I Gusti Ketut Jelantik ditinggalkan sendirian. Pertempuran sengit berlangsung sampai sekitar jam 16.00, rakyat Buleleng kualahan, mereka lari tunggang langgang.

Pasukan Belanda menyasar istana raja. Besoknya, sekitar pukul 08.00, istana Buleleng terbakar habis (sejarah mencatat, itu terjadi pada 28 Juni 1846). Akibatnya, rakyat berlarian, berduyun meninggalkan kampung, dan raja bersama patihnya I Gusti Jelntik pun ikut lari menuju desa Jagaraga. Di sana mencari perlindungan pada rakyat dan membangun banteng pertahanan.

Bagian Kedua (pupuh Sinom), awalnya diceritakan bahwa I Gusti Ngurah Made (raja) didatangi oleh I Gusti Gde Ngurah (adiknya) ketika berada di Jagaraga. Adiknya menyatakan minta maaf, karena tidak dapat banyak membantu sampai kakaknya seperti itu. Mungkin kemudian, apabila mereka (Belanda) datang lagi kemari, adinda siap menjadi pemimpin dalam perang. Raja menjawab sambil menangis, "ya malang benar adinda punya saudara pengecut, menyebabkan adinda menderita". Pada saat itu juga datang seorang tokoh I Gusti Made Jungutan, yang berpendapat, kalau bisa baik Ratu (raja) lakukan daya upaya, minta maaf saja kepada pihak Belanda tentang segala kesalahan yang dilakukan oleh Ketut Jelantik. Dengan cara itu, mereka akan menaruh belas kasihan kepada kita dan berbaik kembali. Tampaknya di sana Raja dan saudaranya, dapat menerima nasehat I Gusti Made Jungutan, dan kini menyerahkan kebijakan itu kepadanya. Di sana para punggawa yang menyertainya, seperti sepakat dengan nasehat itu, dan siap mendukungnya. Akan tetapi, sebaliknya, I Gusti Ketut Jelantik diam saja, seperti tidak setuju. Dia orangnya berpendirian teguh, mengatakan diri kuat dan kebal. Demikian pembicaraan yang muncul awalnya di Jagaraga. Tetapi berikutnya, datang pasukan dari raja Bali lainnya, seperti: Klungkung, sekitar 1650 orang, Gianyar mengikuti, berkumpul di Jagaraga. Kemudian datang pula pasukan dari Mengwi sebanyak 600 orang.

Dalam kaitan demikian, saudara raja, I Gusti Gde Ngurah mendahului bertemu dengan Tuan Mayor (pimpinan Belanda) di Banjar Jawa (Buleleng). Dalam pertemuan dengan Tuan Mayor, ia diterima, tetapi raja diminta mengganti rugi ongkos perang, makanan, peluru yang dihabiskan dalam perang. Raja merasa sulit. Tampak keadaan semakin terasa genting.

Pada bagian kedua (akhir) dari Pupuh Sinom itu, diceritakan bahwa Raja Lombok akan melaksanakan upcara yadnya dan mengundang raja-raja di Bali. Setelah selesai melakukan upacara, datang utusan dari Bali sebanyak 3 orang yakni: I Gusti Made Jungutan, Ida Bagus Tamu, dan seorang brahmana dari desa Bungaya. I Gusti Made Jungutan bersama temannya menyampaikan kepada Raja Lombok, prihal keadaan di Buleleng sudah direbut oleh Belanda, dan berharap raja dapat membantunya. Putra paduka di Karangasem dan Singaraja berharap agar raja-raja di Bali berbaik kembali. Kembali dari Lombok, utusan menyampaikan pembicaraannya kepada Raja Buleleng. Mendengar penyampaian utusan yang ke Lombok - kurang mendapat dukungan - raja I Gusti Ngurah menjadi marah, kecewa, mengatakan diri sudah dibuang. Namun itu tidak membuat semangat Raja Buleleng menjadi habis untuk melakukan tindakan menghadapi musuh. Waktu itu, sepakat, Buleleng, Karangasem, Klungkung bersatu menghadapi musuh. 
Kemudian terdengar, Tuan Mayor meninggal di Betawi, maka semangat perjuangan tumbuh kembali. I Gusti Ketut Jelantik, mendengar kematian pemimpin Belanda itu, lalu berkata, "Telah sepantasnyalah engkau mati, Si Mayor mati kualat". Keberanian I Gusti Ketut Jelantik yang ngotot ingin melawan terus, terdengar juga sampai ke telinga pasukan Belanda. Maka I Gusti Ketut Jelantik dipandang sebagai tikus yang dimaki-maki seperti akan menyeberang kawah, tiada memandang kiri dan kanan, dan setiap berbuat berakibat kehancuran. Cerita ditutup sampai di sini.

\section{Analisis GRB Bagian Pertama (Pupuh Durma)}

GRB ditulis dalam Bahasa Bali dan terjemahan bahasa Indonesia. Pada bagian ini kajian dipusatkan pada usaha menemukan nilainilai yang terkandung di dalamnya. Sebagai unit analisis, sasaran diarahkan pada bagianbagian yang lebih kecil, bagian dari pupuh, yakni bait-bait yang memberikan petunjuk tentang nilai-nilai tersebut. Untuk menunjukkan unsur pupuh dan bait maka pada penulisannya digunakan kode I (pupuh Durma) dan II (pupuh Sinom). Apabila ditulis, I. 3, artinya itu menunjuk pada pupuh Durma, bait 3 . Bila ditulis, II.5, artinya menunjuk data dari pupuh Sinom, bait 5.

Dilihat dari segi teori, analisis ini merupakan "penelitian sastra dengan model analisis konten". Disebut, model analisis ini merupakan model baru, maksudnya, ketika peneliti ingin mengungkapkan, memahami pesan-pesan dari karya itu (Suwardi, 2003: 160).

Nilai politik-hukum dan nilai moral/etika. Pada bagian pertama tampak nilai-nilai, seperti: nilai politik/hukum (pasobaya), yang dilakukan oleh Belanda di Bali dan Lombok. Dalam sejarah tercatat, bahwa raja-raja di Bali dan Lombok telah melakukan perjanjian dengan Belanda pada tahun 1843. Hal itu dilakukan - dalam perspektif Belanda - untuk mengatasi berlakunya hukum tawan karang, yang melarang kapal-kapal asing datang di perairan Bali, Lombok tanpa izin dari raja (Utrecht, 1962: 174). Isi perjanjiannya adalah:
"Yen ada perahu kandas, karusakan ring paswan salih tunggil, apang da mangarampas, manjarah tawan karang, dening ya memanggih sakit, kawenangannya olasin ya tulungin ditu".

Artinya:

Apabila ada perahu kandas, kerusakan pada salah satu kuala/pelabuhan, tidak boleh dirampas, di tawan karang, karena mereka mendapat bahaya, tetapi harus ditolong (GRB, I,5).

Dilihat dari konten, wacana yang muncul, tampak bahwa semua perjanjian itu merupakan siasat, perspektif pemerintah Belanda dalam rangka mempermudah geraknya di perairan dan memberi arti bahwa wilayah raja-raja itu menjadi wilayah kekuasaan Belanda. Di sini tampak nilai kuasa politik kolonial mendominasi keadaan waktu itu.

Kemudian diceritakan, ada sebuah perahu dagang sedang kerusakan di pangtai Sangsit, dirampas. Sejarah mencatat, bahwa peristiwa itu terjadi pada tahun 1844. Pihak pemerintah Belanda memanfaatkan peristiwa itu. Tuwan Besar (Gubernur Jendral) di Betawi menjadi marah, ingin menuntut agar Buleleng mengganti rugi barang-barang perahu yang dijarah. Dan berusaha menghubungi Raja Klungkung agar menasehatinya, tetapi tidak dapat meredakan kemarahan I Gusti Ketut Jelantik yang merasa dilanggar hak-haknya. Disebutkan dalam GRB:

"Tuwan Besar berangti, mahutusan ka Bali mangawa surat, I Gusti Ketut Jelantik sampun kapitelas ngenemin, nampi surat, kocap munyine ditulis I Tuwan Besar jani ya menagih". Sababwatan perahune kajarahin di Sangsit tagiha makejang, tur iya ngawatang raja Buleleng tan tindih ring pasobaya ne makranan becik" (GRB.I, 17-18).

Artinya:

Gubernur Jendral Belanda marah, mengirim utusan ke Bali membawa surat. I Gusti Ketut Jelantik sudah diserahi menerima utusan itu. Bunyi surat itu, "Gubernur Jendral menagih seluruh barang yang dirampas pada perahu di Sangsit, dan Belanda menuduh 
bahwa Raja Buleleng tidak mentaati perjanjian yang menyebabkan baik.

Dengan itu, I Gusti Ketut Jelantik menjadi sangat marah, serta protes, kata-katanya tak karuan, sementara raja tidak punya pendapat, acuh tak acuh pada sikap marah I Gusti Ketut Jelantik.

"Boya tityang mangrandah bahita kandas, Kandane sapuniki. Ipun perahu dagang melabuh ring pabeyan, tan manut krama iriki, paswaran bangsal purug ipun iriki' (GRB.I, 33). "Punika dawning tityang mangrandah, apan mula pemargi. Yan tan asapunika, doh kapimanah tityang kadi ngarihinin muncit" (GRB.I, 34).

Artinya:

Bukannya hamba menjarah perahu kandas, soalnya begini, itu perahu dagang berlabuh di pabean, tidak sesuai aturan di sini, aturan pelabuhan dilanggarnya. Itu sebabnya, kami menjarah, memang begitu aturan. Bila tidak demikian, jauh rupanya hamba akan berani mendahului Tjokorda.

Sampai di sini tampak, bahwa sikap I Gusti Ketut Jelantik yang terus menentang, merupakan bagian dari nilai sikap moral mempertahankan kebenaran (hak) atas wilayah yang sudah memiliki aturan hukum sendiri. Tampak bahwa dari sisi pikiran Raja Buleleng dan patihnya, jelas bahwa ia ingin mempertahankan kekuasaannya dan akan melawan siapa pun yang berani merampasnya. Nilai, semangat kepahlawanan I Gusti Ketut Jelantik teruji di sini. Dengan keberanian pihak Buleleng menyampaikan pikirannya (menentang), maka pihak Belanda tidak dapat menerima, lalu menyiapkan pasukan, serdadu untuk menyerang Buleleng.

"Tan kocapan di jalan rawuh di Pabeyan kapale pajegirgir, sami kapal perang, sakotor sakonyer, wangkang julungjulung, kapal api dadi prakarya ngenter kapale sami" (GRB.I, 64). Artinya: Tidak diceritakan di jalan, datanglah di Pabeyan kapal-kapal besar yang bernama sakotor, sakonyer. Kapal yang besar menjadi pemimpin itu semua. "Pasemengan I Tuwan Mayor manuhunang suradadune sami makatigangatak, sampun pada madabdab, banban pejalane gilik, ada mapencar, panjawat kanan-keri" (GRB.I, 71).

Artinya:

Pagi-pagi I Tuwan Mayor sudah menurunkan tentaranya semua sebanyak 600 orang, setelah bersiap, berjalanlah perlahan-lahan.

Dalam sejarah tercatat, bahwa pasukan Belanda dalam jumlah besar datang di Pabeyan, Buleleng pada tanggal 27 Juni 1846 (Kartodirdjo \& (dkk.), 1977: 200)).

Dalam situasi demikian, di desa Buleleng masyarakat sudah membangun bentengbenteng pertahanan untuk menghadapi kedatangan musuh. Ketika serdadu (musuh) datang, masayarakat Buleleng sudah siap menghadapi, kedua kelompok saling bersorak menandakan kesiapan masing-masing. Dalam GRB disampaikan demikian.

"Di desa Buleleng sampun nangun gelar, katah wang kampung Bugis, nggama jroning desa, wang Bali masarengan, Gusti Ketut nyenapati, raris karegah munyin bedile titir" (GRB.I, 72). "Mahusungan surake nimbal katimbal, pada saling timbalin, anging selat gelar, suradadune ngregah, tuara ngitung tatu kanin, pada lagawa nyidayang kayun gusti" (GRB.I, 73).

"I Twan Mayor membedil saking bahita, munyin bedile tarik, meriem muah lela, kadi gelap sajuta, limut bahan andus bedil, Bhatara Surya remrem mateja kuning" (GRB.I, 75).

Artinya:

"Di Buleleng, masyarakat sudah membuat benteng, banyak orang kampung Bugis ikut berjaga, bersama orang-orang Bali. I Gusti Ketut Jelantik sebagai pemimpinnya, lalu disambut suara bedil yang tidak berkeputusan". "Sorak sorai gemuruh saling berganti dari luar batas benteng. Serdadu Belanda menyerang tidak menghitung bahaya. Sekalian ikhlas berperang mengikuti kehendak pemimpinya".

"Pemimpin pasukan Belanda menembak dari kapal, suara bedil gemuruh tidak berkeputusan seperti suara sejuta halilintar, diselimuti asap mesiu. Bhatara 
Surya remang-remang, berwarna kuning".

Dengan kejadian demikian, tampak pasukan kerajaan menjadi kocar-kacir, tidak mampu bertahan, sehingga I Gusti Ketut Jelantik sepertinya bertahan sendirian. Para pengikutnya, setelah banyak yang meninggal, banyak yang meninggalkan medan perang, menyelamatkan diri mereka. Istana Singaraja pun akhirnya dibakar, dihancurkan musuh, membuat pasukan kerajaan menjadi putus asa sama sekali. Pada akhirnya, I Gusti Ketut Jelantik pun tidak dapat bertahan dalam menghadapi kekuatan musuh, dan ikut menyingkirkan diri.

"Pasemengan ring coma pwon
dungulan suradadune malih, mara
malaksana manggebug Singaraja,
munyin bedile titir, wang Singaraja pada
takut mesuwin" (GRB.I, 84).
Artinya:
Pagi-pagi pada hari Senin Pon, Dungulan
(dua hari sebelum hari Galungan), lagi
serdadu bergerak menggempur kota
Singaraja, suara bedil tidak berhenti-
henti, warga Singaraja takut ke luar.
"Sakewala ngalawan saking jroning
desa, sok mesiat ban bedil, surak
sinurakan, sawatara dawuh tiga sagetan
puwun di puri di Singaraja, bedil bome
muwunin" (GRB.I, 85).
Artinya:
Tetapi melawan dari dalam desa,
berperang dengan bedil, saling sorakin,
dan sekitar pukul 08.00, tiba-tiba kota
Singaraja terbakar.

Sejarah mencatat, bahwa itu terjadi tanggal 29 Juni 1846 dan pasukan Belanda menduduki kota Singaraja (Kartodirdjo \& (dkk.), 1977: 201). Namun semangat kepahlawanan I Gusti Ketut Jelantik tetap membara, meskipun harus menyelamatkan diri, menyingkir ke Desa Jagaraga.

Dari catatan di atas, Nampak bahwa di sini muncul nilai kebersamaan antara raja dan rakyatnya, bersama-sama membela, mempertahankan wilayah Buleleng yang diserang pasukan musuh. Peristiwa itu juga memberi pelajaran, pendidikan kepada generasi berikutnya, betapa generasi terdahulu berjuang mempertahankan kemerdekaannya.

\section{Analisis GRB Bagian Kedua (Pupuh Sinom) Nilai-nilai persatuan dan kompetisi/diplomasi politik}

Berkaitan dengan kepahlawanan I Gusti Ketut Jelantik, bagian ini tidak benyak bercerita. Awal cerita menuturkan keadaan di Desa Jagaraga. Raja dan Patih I Gusti Ketut Jelantik sudah berada di sana. Pada saat itu, datang saudara raja (adiknya) menemui raja di Jagaraga, menyatakan maaf dan mendukung perjuangannya. Disebutkan.

"Ida Gusti Gede Ngurah nyalempoh raris menangis, kangen ring rakane reko, ngelut cokor matur aris. 'Ampura tityang beli, kasep kapo tityang rawuh, doh tityang nubalihang keweh beline iriki, dumadakang wenten sih ican batara" (GRB.II, 1).

Artinya:

Ida I Gusti Gede Ngurah bersimpuh, memeluk kaki, lalu menangis, karena merasa kasihan kepada kakaknya (raja). 'Mohon maaf dinda kepada kakanda, terlambat datang, tak mungkin dinda akan melihat saja kesulitan kanda di sini. Semoga ada anugrah Hyang'.

"Menawi te benjang puwan ipun malih mangwawanin, magebug ke Jagaraga, irika tityang mapamit, pucukang dadarin, sampunang beli bas lacur, wilang tityang I Wolanda ngrobok segara, kalilih, ica beli irika ngadeg macingak" (GRB.II, 2).

Artinya:

Barangkali besok atau lusa mereka lagi memulai memerangi ke Jagaraga, di sana dinda akan meminta, dahulukan dinda menjadi pemuka, jangan kakanda merasa rendah, kanda rasa I Wolanda seperti menerebak samudra, akan kalah. Harap kanda dapat menyaksikan.

Kata-kata adik raja di atas seperti memberi dukungan, semangat kalau raja masih bisa melawan, dan berhasil. Di sini muncul nilai kebersamaan dari saudaranya untuk berbela, mengatasi keadaan. Akan tetapi ada juga yang berpendapat, agar raja mau berdamai, meminta maaf, seperti disarankan oleh I Gusti Made Jungutan, menunjukkan adanya nilai diplomasi, politik dalam mengahadapi musuh. GRB menulis demikian. 
"Para punggawa makejang sahur manuk mamisinggih. Gusti Ketut Jelantik meneng, rupa kadi manyenggladin, mula daginge daki, pangrawose teguh timbul, bikase nguragada, ngaku aeng, ngaku sakti, sangkan pamuktine kene embad" (GRB.II, 10).

Artinya:

Para punggawa semuanya kompak mendukung. Tetapi Gusti Ketut Jelantik diam, seperti tidak setuju, memang isinya kotor, kata-katanya selalu tinggi, prilakunya angkuh, mengaku sakti, kebal. Dan karena itu, buktinya begini hancur.

Akan tetapi, I Gusti Ketut Jelantik mendengar percakapan itu, tampak diam, tidak setuju, meskipun para punggawa menyatakan persetujuannya. Bersamaan dengan itu, rajaraja lainnya di Bali, semakin memberi dukungan pada perlawanan yang dilakukan Ketut Jelantik. GRB mengungkapkan demikian.

"Keto kocapannya tuturan munggah ditulis, pangrawos di Jagaraga, kocap dinane ne mani akeh rawuh pamating, sikepe saking Klungkung sawatara sepaha seket, Gianyar menyarengin, Dewa Ketut Agung rawuh kairingang" (GRB.II, 11).

Artinya:

Begitu cerita yang sudah dicatat pembicaraan di Jagaraga. Disebut dihari besoknya datang banyak pasukan berani mati dari Klungkung, sekitar 1650 orang, Gianyar juga mengikuti, dipimpin oleh I Dewa Ketut Agung.

Ungkapan di atas menunjukkan betapa rajaraja di Bali menunjukkan rasa kebersamaan, nilai persatuan muncul. Akan tetapi keadaan masyarakat, juga digambarkan sebagai banyak yang putus asa, mengeluh payah mengikuti semangat I Gusti Ketutu Jelantik. Disebutkan dalam GRB.

"Kocapa ucap-ucapan, panjake ne pada sedih, rarud sambeh paberasat nyadcad Gusti Ketut Jelantik, 'kene san dadi pepatih, twara ko manawang tutur, sok nuhukin mamadat, kalegane padidihin manggugonin daya pikena ken rowang" (GRB. II. 13).
Artinya:

Seperti dikabarkan, rakyatnya yang pada bersedih berduyun sama menyingkir, menyesalkan I Gusti Jelantik dan berkata, 'begini saja menjadi Patih, tidak tahu tatwa (kemanusiaan), hanya memenuhi kesenangan sendiri, minum/memadat, senangnya sendiri, menggunakan daya upaya yang menguntungkan diri sendiri'.

Ungkapan pengarang GRB ini dapat juga dilihat dari sudut nilai pendididikan, bahwa kebiasaan minum, memadat dari I Gusti Ketut Jelantik, dikeluhkan oleh masyarakat. Selanjutnya, tuntutan pemerintah Belanda tampak sangat memberatkan Raja Buleleng, sehingga sulit akan diwujudkan. Keadaan itu pula tampak tetap mendorong semangat untuk mempertahankan kekuasaan. Dan pihak Belanda tetap berusaha untuk menaklukan total kerajaan Buleleng.

Kata-kata I Gusti Jelantik seperti itupun kedengaran sampai ke Jawa, pada pihak Belanda, sehingga tampak pihak Belanda terus bersiap, berusaha mematahkan perlawanan I Gusti Ketut Jelantik. Sampai di sini tampak, bahwa pihak Belanda akan terus bergerak mengepung persembunyian Raja dan Patih I Gusti Ketut Jelantik. Memang pergolakan belum selesai. I Gusti Ketut Jelantik sebagai pemimpin perlawanan bertahan di Jagaraga. Ketegangan masih menghantui keadaan dalam membela harga diri dan wilayah (bangsa). Cerita GRB diakhiri sampai di sini, meski perjuangan belum selesai.

\section{SIMPULAN}

Dari uraian di atas, dapat disampaikan bahwa Gaguritan Rusak Buleleng, koleksi Gedong Kirtya, memberikan gambaran mengenai peristiwa sejarah eroik di Bali Utara dalam kerangka perluasan pengaruh kekuasaan colonial Belanda di kepulauan. Peristiwa itu terjadi pada tahun 1846, menyebabkan kerajaan Buleleng jatuh ke tangan penjajah Belanda. Pada masa itu situasi menunjukkan bahwa kekuatan politik Belanda sedang meluaskan pengaruhnya di Kepulauan Indonesia. Bali mulai menjadi sasaran pemerintah kolonial di pertengahan abad ke-19.

Pengaruh Pemerintah Belanda mulai masuk dengan memutus mata rantai perangkat "hukum 
tawan karang" yang sudah lama berlaku di Bali dan Lombok. Meskipun pihak Bali berkeberatan hukum tawan karang dihapuskan, namun dengan upaya politik diplomasi yang cerdik dari Belanda, hukum tawan karang dapat dirombak. Dihapusnya hukum tawan karang itu pada dasarnya menimbulkan konflik-konflik politik antara raja-raja Bali-Lombok dengan pihak Pemerintah Belanda. Namun karena kekuatan pasukan Belanda yang besar dengan persenjataan modern yang lengkap, sementara pasukan kerajaan menggunakan senjata tradisional (keris, tombak), maka kekuatan perlawanan Bali-Lombok dapat dikalahkan.

Namun tidak dapat dipungkiri, bahwa pergolakan yang terjadi tidak lepas dari nilainilai sitem budaya yang mendasarinya. Mengenai nilai-nilai yang dapat digali dari cerita GRB dapat disebutkan: nilai persatuan, kebersamaan, kepahlawanan, nilai pendidikan, nilai politik/diplomasi, dan nilai kompetisi kuasa politik antar kekuatan politik. Berkaitan dengan teori, penggunaan model analisis konten relevan di dalamnya. Berbagai konteks situasi, system nilai budaya berpengaruh di dalamnya. Tampak berpengaruh system nilai guyub, rasa persatuan orang Bali, nilai kompetisi politik raja-raja Bali, nilai tradisi masyarakat Bali, dan system politik kolonial yang sedang berkembang. Dari cerita GRB mengenai pergolakan di Bali Utara, kepemimpinan, semangat kepahlawanan I Gusti Ketut Jelantik menonjol.

\section{DAFTAR PUSTAKA}

Bali-Indonesia, P. P. K. (1978). Kamus BaliIndonesia. Dinas Pengajaran Propinsi Daerah Tingkat I Bali.

Kartodirdjo, S., \& (dkk.). (1977). Sejarah Nasional Indonesia. Balai Pustaka.

Koentjaraningrat. (1974). Kebudayaan, Mentalitet dan Pembangunan. PT Gramedia.

Suwardi, E. (2003). Metodologi Penelitian Sastra. Epistemologi, Model, Teori, dan Aplikasi. Universitas Negeri Yogyakarta.

Utrecht, E. (1962). Sedjarah Hukum Internasional di Bali dan Lombok. Sumur. 